\title{
Fascia lata rack for retinal detachment
} surgery

\author{
P. N. HENDERSON, J.-M. PAREL, AND G. W. GROGK
}

From the Melbourne University Department of Ophthalmology, the Ophthalmic Research Institute of Australia, and the Royal Victorian Eye and Ear Hospital, Melbourne

The use of biological polymers for external plombage in retinal detachment surgery is well established (Havener and Wachtel, I964; Klöti, I964; Crock and Galbraith, 1966). Fascia lata is the tissue most widely employed because it is readily obtainable and is easily sterilized and stored (Havener and Olson, 1962). When tightly twisted it makes an ideal encircling element for scleral buckling.

This paper describes an instrument which facilitates the production of firm uniform cords from strips of fascia lata.

\section{Instrumentation (Fig. I)}

The rack consists of a pair of toothed clamps mounted on vertical columns. When in use it is screwed perpendicular to the base (Fig. 2). Torque is applied to the fascia by a clamp which can be rotated about the horizontal axis and locked in any desired position. The twisted tissue is pulled taut by sliding one of the columns along a horizontal bar. This sliding system permits the distance between clamps to be varied from 50 to $170 \mathrm{~mm}$. It can be locked anywhere within this range.

The base of the instrument is a shallow open box, inside which the rack is screwed for storage and sterilization (Fig. 3).

\section{Technique}

A strip of autogenous or irradiated cadaver fascia lata is trimmed to the desired width and folded on its long axis. The two ends are then clamped, and twisting and straining is applied until the desired cord diameter is attained. The instrument is locked and the central portion of the cord, which will be used to produce a scleral buckle, is stabilized by a running $5-0$ plain cat-gut suture. The suture is inserted with a straight needle in the form of a key-hole stitch which is doubled back on itself in a plane at right angles to the first run. Interrupted stitches are then placed at $1 \mathrm{~cm}$. intervals along the sutured cord (Fig. 4, overleaf).

After the scleral buckling procedure has been effected, the fascia lata at each end of the cord is untwisted, thinned by scalpel or scissors, and passed around the globe as an encircling element (Fig. 5, overleaf).

\section{Discussion}

Cryopexy and full-thickness scleral buckling for the repair of retinal detachment is now the standard procedure at the University of Melbourne Department of Ophthalmology. Scleral buckling is produced by tying mattress sutures over a twisted cord of fascia lata.

The instrument described was designed to enable an assistant to prepare a suitable cord of fascia while the surgeon prepares the eye for cryopexy and buckling. The cord so produced is firmer and more uniform than one fashioned manually. 


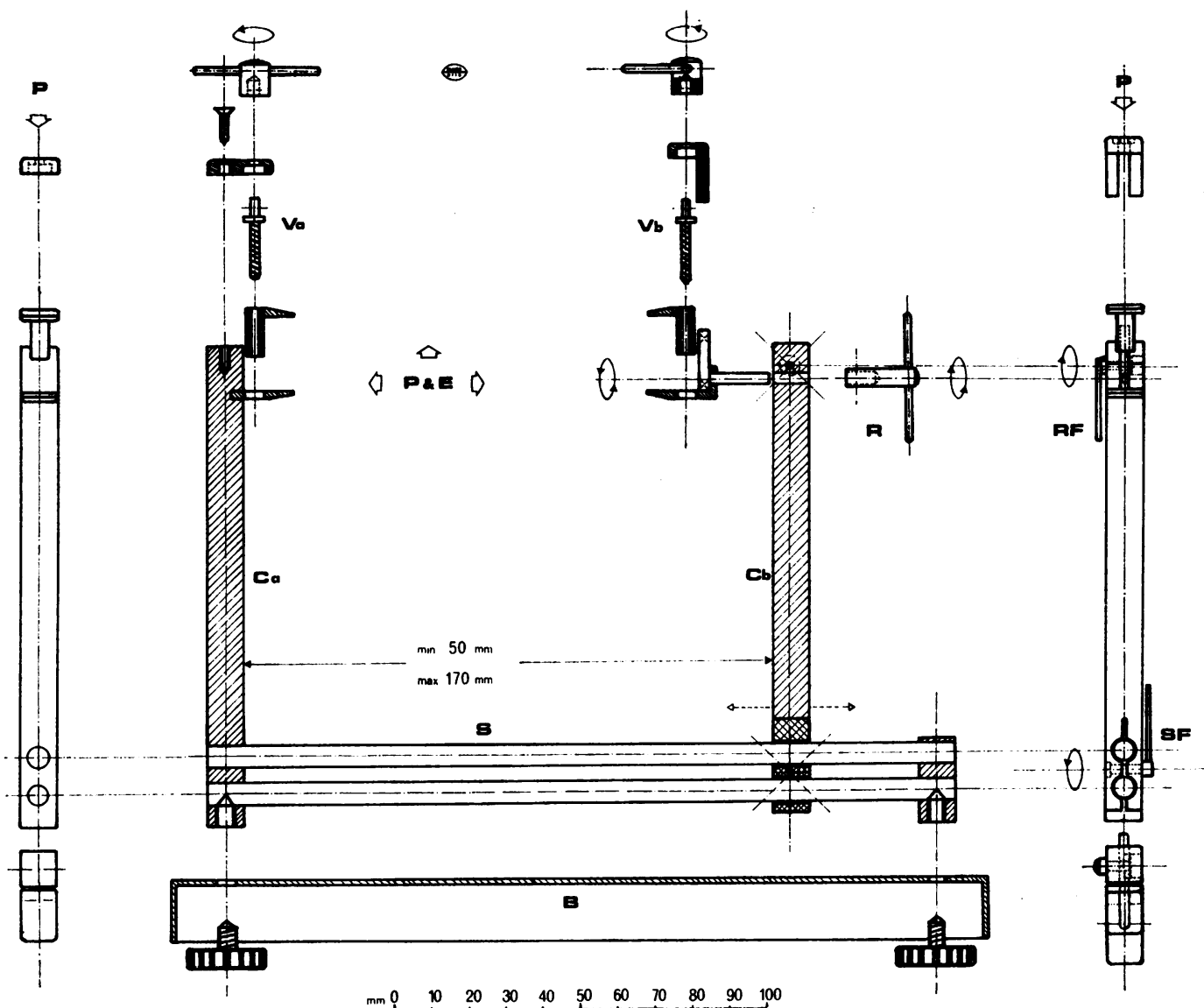

FIG. I. Design drawing of fascia lata rack

P projection;

B base;

Ca fixed column;

$\mathrm{Cb}$ sliding column;

S horizontal bars permitting adjustment of distance between clamps (range 50 to $170 \mathrm{~mm}$.); SF sliding column lock;
Va fixed fascia clamp;

$\mathrm{Vb}$ rotatable fascia clamp;

$R$ rotating levers;

$\mathrm{RF}$ rotatable clamp lock

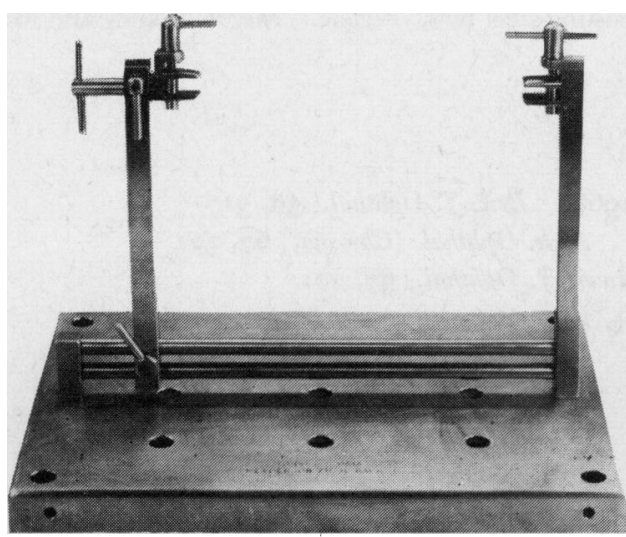

FIG. 2 Instrument ready for use. Rack screwed perpendicular to base

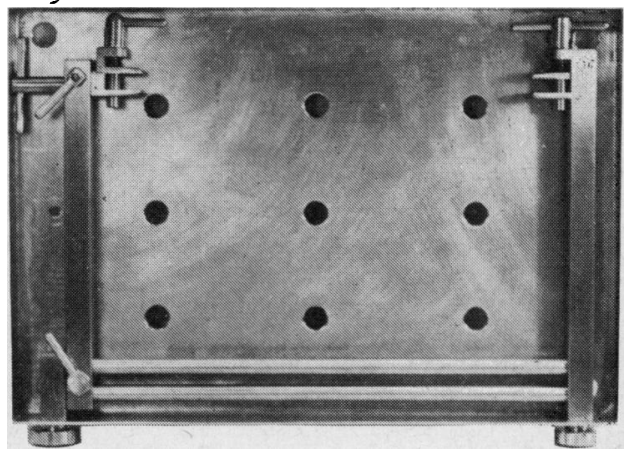

FIG. 3 Sterilization position. Rack screwed inside base 


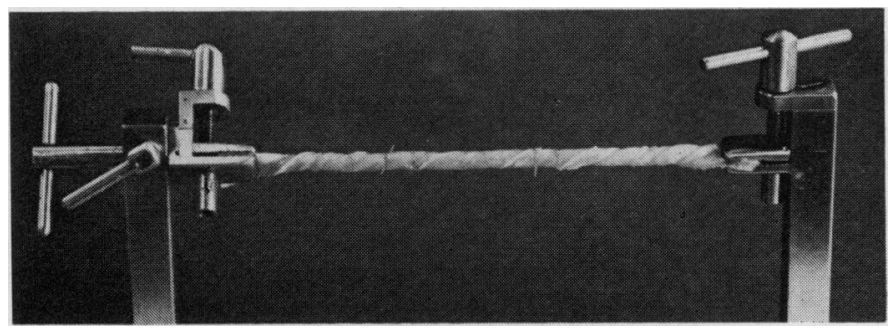

FIG. 4 Twisted fascia lata cord sutured in central portion with continuous and interrupted $5^{-0}$ catgut stitches
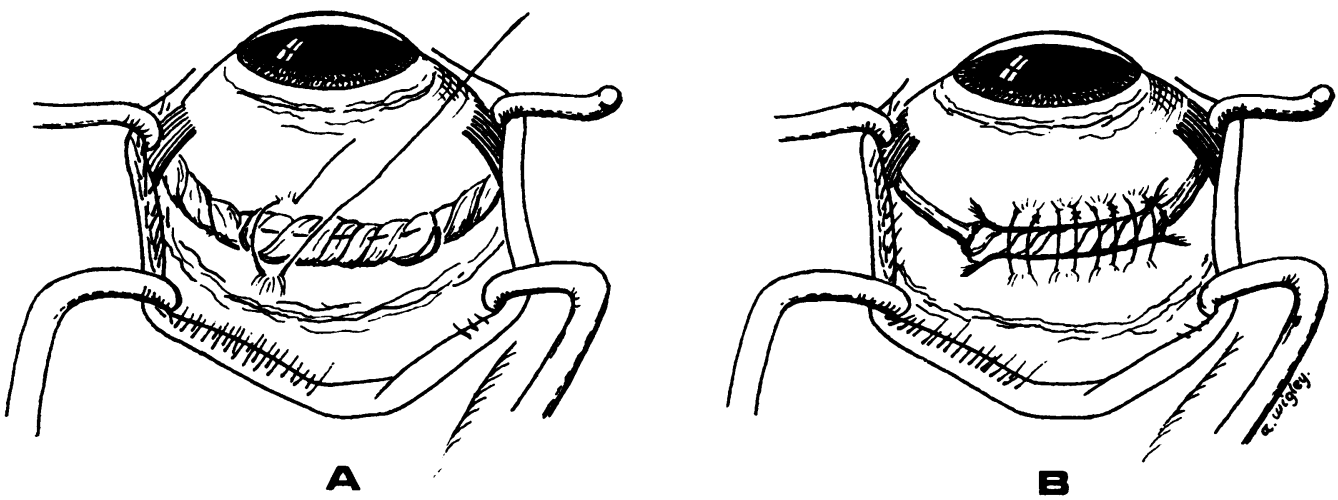

FIG. 5. Twisted fascia lata cord in use

A. Scleral buckling with $5^{-0}$ braided dacron mattress sutures

B. After scleral buckling the fascia at each end of the cord is thinned and passed around the globe as an encircling element

\section{Summary}

An instrument is described which twists fascia lata into a cord for encircling plombage in retinal detachment surgery. The implant, which can be produced rapidly without assistance, is firmer and more uniform than one fashioned manually.

The instrument was made from corrosion resisting steel by L. Pericic. Mr. A. Wigley and Mrs. G. Van den Brenk were responsible for the illustrations.

\section{References}

GROCK, G. W., and Galbraith, J. E. K. (I966) Brit. F. Ophthal., 50, 5 I 7

HAVENER, W. H., and olson, R. S. (1962) Arch. Ophthal. (Chicago), 67, 72 I

- - and WAGHTEl, J. G. (1964) Amer. J. Ophthal., 57, 201

кı.̈̈ті, R. (1964) Ophthalmologica (Basel), 147, I 49 